\title{
Application of analytic hierarchy process for analysis of impact significance in EIA of oil and gas industry
}

\author{
Stephen C. Theophilus*, Tominayingibo L. Fubara-Manue, Babatunde Anifowose
}

\begin{abstract}
Impact significance determination is one key task required of all EIA undertakings. A major issue in EIA analysis is the subjectivity resulting in, inconsistencies in experts' and stakeholders' judgment. However, Analytic Hierarchy Process (AHP) can serve as a check for inconsistencies and tool for aggregation of the different experts' and stakeholders' opinions on impact assessment. This study investigated the integration of AHP into EIA impact significance determination to assess the effect of consistency and inconsistency in stakeholder judgments. A case study to investigate an application of the proposed method in a major oil pipeline's replacement project is presented. It was observed that the opinions of both experts and stakeholders were uniform on some impacts such as land use, water contamination and an increase in the cost of health services, representing $18.75 \%$ of all the identified impacts. Conversely, there were differences in opinions on other impacts revealing what could be a cause of serious disagreement between the company and the community. It was also observed that, although consistency in judgment is critical, it is not always very easy to obtain when dealing with many stakeholders. This integration demonstrated the ability of AHP to serve as an excellent decision aid for managers during environmental impact assessment. This could also help authorities prioritise risk management plan and allocate resources optimally when dealing with identified impacts of a project.
\end{abstract}

Keywords - impact significance determination, environmental impact assessment, analytic hierarchy process, oil and industry, multiple-criteria decision analysis.

\section{Introduction}

Environmental Impact Assessment (EIA) has become an important tool of almost all project assessment carried out across in developed countries as a way of promoting good environmental decisions. According to Wood (2008), every EIA should fully identify and analyse potential impacts and relay these to experts and the public at every stage of the process. The identification of 'significant impacts' that exceed prescribed safety is termed 'Impact Significance'. It is seen as the most important aspect in EIA (Lawrence 2007) and is widely accepted to be the magnitude of the impact and the sensitivity of the receptor Khadkaet al. (2011). Mathematically, this could be stated as:

$\begin{array}{ccc}\text { Impact } & \text { Impact } \\ \text { Characteristics } \\ \text { (Magnitude) }\end{array} \quad X \quad \begin{gathered}\text { Importance } \\ \text { (Value) }\end{gathered} \quad \begin{gathered}\text { Impact } \\ \text { Significance }\end{gathered}$

*Stephen C Theophilus

School of Energy, Construction and Environment

Coventry University, Priory Street Coventry, Cv1 5FB

United Kingdom
Considering the possible impact of crude oil exploitation on the eco-system, EIA is regarded as a crucial aspect of all oil and gas related projects. However, because significance determination involves subjective opinions of experts and members of the immediate society, it is prone to inconsistency and some level of uncertainty (Tenney et al 2006). Therefore, some outcomes of the EIA process relayed to the public at some stage has caused problems for the oil and gas companies and their host communities

There has, however, been much work agreeing to the fact that the application of Multi-Criteria Decision Making (MCDM) offers a well-needed improvement in the decisionmaking process. This is evident in the work of Huang, Keisler and Linkov (2011) and also in public acceptance as was repeatedly emphasised Glucker et al. (2013).

Whilst there are reports of application of AHP, in areas such as management (Dong and Cooper 2016), aviation (Singh and Nachtnebel 2016), logistics (Tavana et al. 2016), tourism (Wang et al. 2016), , there are few known study of potential application of AHP in Impact Significance determination in the oil and gas industry. The main aim of this research was to investigate the effect of consistencies and inconsistencies in judgements from experts and stakeholders in the oil and gas industry through the use of AHP in the EIA process. It considered that the findings of this study could assist impact assessors in obtaining a more reliable and acceptable EIA and reduces clashes between communities and the oil and gas companies. The findings will also help the government make stricter regulations about public participation not only at the scoping stage of oil and gas related EIAs but also in the impact prediction stage.

\section{Methodology}

\section{A. Research Method}

The Analytic Hierarchy Process (AHP) as developed by Saaty (1987). between 1971 and 1975 was used for this research. AHP is a multiple criteria decision making (MCDM) tool that use scales which reflect the relative opinions of a person or a group of people about a particular problem or decision. Details of the methods have been previously described elsewhere Saaty and Ozdemir (2003). However, briefly, decision-making using the AHP, involves the following processes:

1. Defining and structuring the decision problem and obtaining a pairwise matrix.

2. Calculating the priorities

3. Checking for Consistency using a consistency ratio CR. Saaty noted that judgements for any pairwise matrix of any problem with a $\mathrm{CR} \geq 0$. 1 were considered inconsistent. Moreover, Saaty (1987) further showed that consistency ratio $\mathrm{CR}$ is defined as:

$\mathrm{CR}=\mathrm{CI} / \mathrm{RI}$ 
Proc. of the Fourth Intl. Conf. Advances in Bio-Informatics, Bio-Technology and Environmental Engineering- ABBE 2016 Copyright $\odot$ Institute of Research Engineers and Doctors, USA .All rights reserved.

ISBN: 978-1-63248-091-0 doi: 10.15224/ 978-1-63248-091-0-62

Where $\mathrm{RI}$, is the random index and $\mathrm{CI}$ is the consistency index which could be defined by Saaty (1987):

$\mathrm{CI}=\left(\lambda \_\max -\mathrm{n}\right) /((\mathrm{n}-1))$

\section{B. Data collection and Analysis}

The instruments used for data collection were questionnaires adapted from Zhou et al. (2015) and Sahin et al. (2013) but related to a major oil pipelines replacement project (Table 1). The questionnaire was designed to give the respondent all the impacts to be considered, say $n\left(a_{1}, a_{2}\right.$, $\left.\ldots a_{n}\right)$; the objective was to determine their preference levels expressed in the $[0,1]$ interval. This is done by undertaking pairwise comparisons of the alternatives and then the results are organised in a $n * n$ reciprocal matrix $A=\left(a_{i j}\right)$ where $a_{i j}=1 / a_{j i}$, for $i \neq j$, and $a_{i i}=1$. This matrix is reciprocal with $a_{i j}$ representing the comparison between impacts $i$ and $j$. To achieve this, the respondents were asked to compare two impacts, $\mathrm{i}$ and $\mathrm{j}$, which impact is thought to be more important and by how much using the 1 to 9 scale proposed by Saaty (1987).

The questionnaires were sent to 15 experts in the field of environmental impact assessment for oil and gas projects. Five of these experts were also academics; thirty-five were members of the public bringing the total number of participants to 50 . The experts are important as they are both knowledgeable about environmental impacts assessment. The public group included members of the oil producing community, authorities and other persons who may be affected by the impact of the project as their participation is essential the success of any project (Ramanathan 2001).

TABLE 1. EXAMPLE OF A PARTICIPANT QUESTIONNAIRE USING THE 1 TO 9 SCALE PROPOSED BY SAATY (1987)

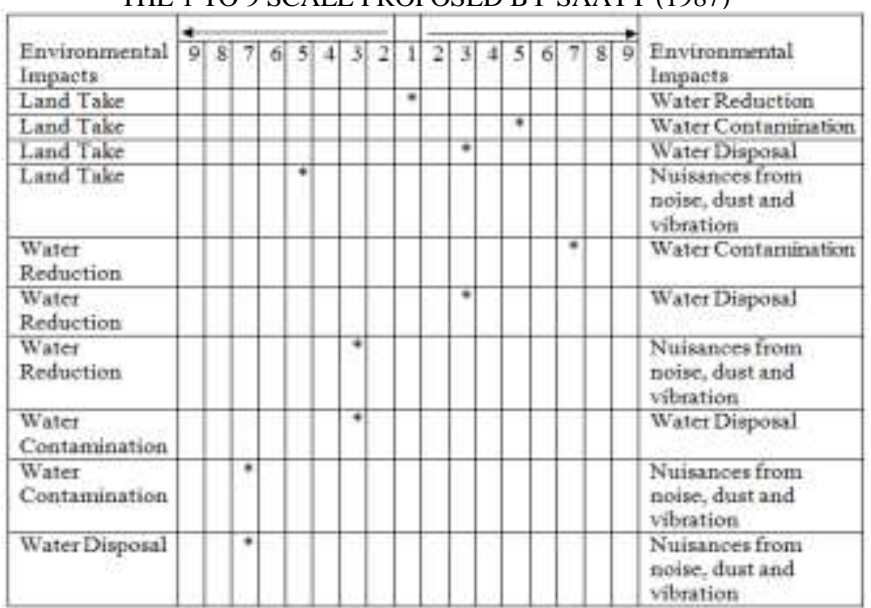

\section{Defining and Structuring the Decision Problem}

Saaty and Ozdemir (2003) in their work suggest that for better consistency, no one hierarchy should have more than seven alternatives and/or criteria. For this reason, the identified impacts for this project were analysed in three groups - environmental impacts, social impacts and health impact with the goal at the top, criteria in the middle and alternatives at the bottom of each hierarchy. Figures 1, 2 and 3 show the hierarchical structuring for the environmental impact, social impacts and health impacts respectively. These were then used to develop a pairwise matrix for these three subgroups.

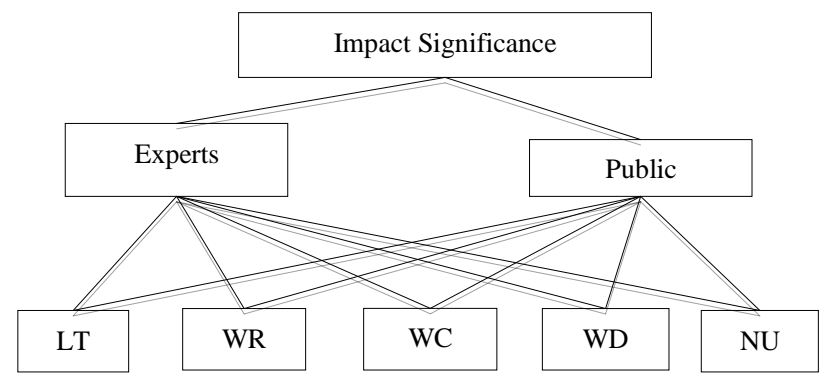

Figure 1. The AHP hierarchy model for Environmental Impacts. (LT -Land Take; WR-Water Reduction; WC-Water Contamination; WD- Waste Disposal; NUNuisances from noise, dust and vibration)

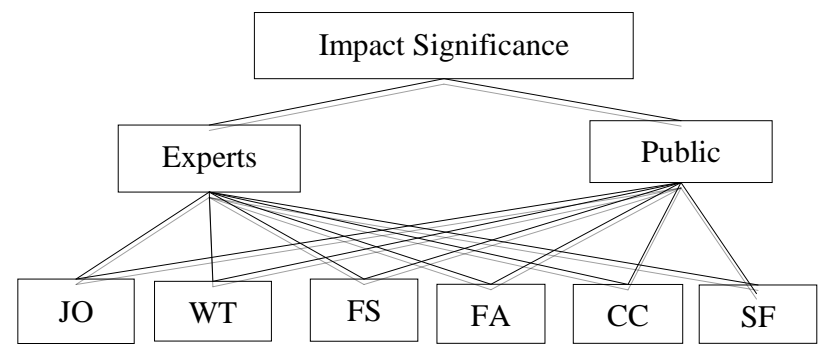

Figure 2: The AHP hierarchical model for Social Impacts. (JO- Increase in Job Opportunities; WT- Increase in Water Traffic; FS- Disruption in Family Structures; FA- Disruption in Fishing Activities; CC-Influx of Construction Crew; SFIncrease in demand on services and facilities in local communities)

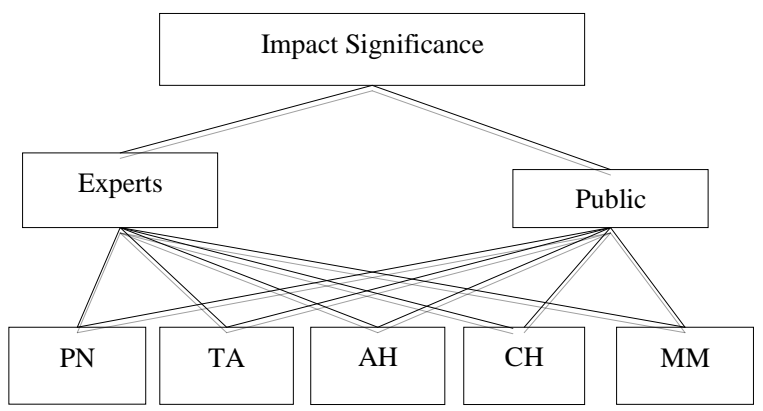

Figure 3: The AHP hierarchical model for Health Impacts. (PN - Poor Nutrition; TA - Increase in Traffic Accidents; AH - Reduction in Access to Healthcare $\mathrm{CH}$ - Increase in cost of health services; MMIncrease in Morbidity and Mortality rates).

Following the AHP process, the local priorities (weights) of all the alternatives were calculated and the consistency of each pairwise matrix checked by calculating for the CI and CR using equation 1 and 2 . The consistent matrices were then aggregated using the geometric mean method to obtain the global priority for each hierarchy. The higher the weight of an impact implied higher rank which in turn meant higher significance

The differences in consistent and inconsistent judgements were also investigated. To do this, the global rankings for all member judgement, for all consistent judgement and for all inconsistent judgement were calculated and compared. 
Proc. of the Fourth Intl. Conf. Advances in Bio-Informatics, Bio-Technology and Environmental Engineering- ABBE 2016

Copyright (C) Institute of Research Engineers and Doctors, USA .All rights reserved.

ISBN: 978-1-63248-091-0 doi: 10.15224/ 978-1-63248-091-0-62

\section{Results and Discussion}

Figures 4, 5 and 6. Show the values for all three groups of impacts and the rankings.

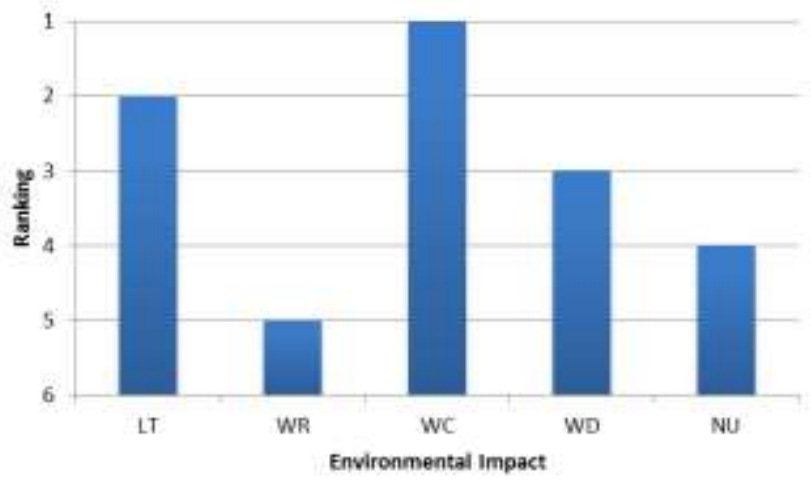

Figure 4: Graph showing the Rankings for Environmental Impacts based on the global weights ( 1 being the most significant impact and 5 being the least significant impact)

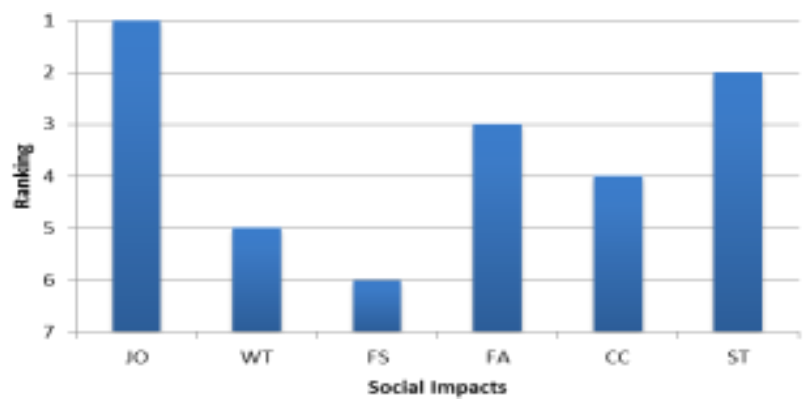

Figure 5: Graph showing the Rankings for Social Impacts based on the global weights $(1$ being the most significant impact and 6 being the least significant impact)

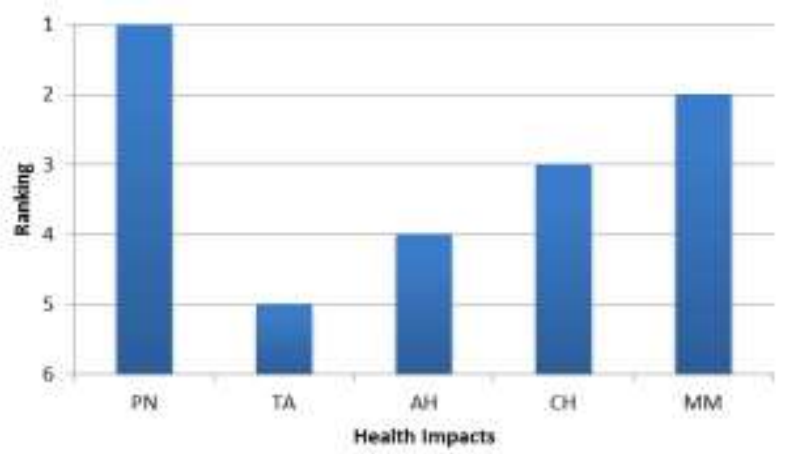

Figure 6: Graph showing the Rankings for Health Impacts based on the global weights ( 1 being the most significant and 5 being the least significant)

According to tables figures 4,5 and 6, Water Contamination (WC) is the most significant environmental impact, Job Opportunities (JO) the most significant Social impact and Poor Nutrition (PN), the most significant Health impact. With this information, Oil and Gas Companies can seek alternatives and/or mitigation measures that take the opinions of both the Experts and the Public into consideration.

It was observed that there were no differences in the rankings for the environmental impacts ( Figure 7). However, there were differences in the rankings when only consistent judgement, only inconsistent judgement and when both were used (Figure 8 and 9).

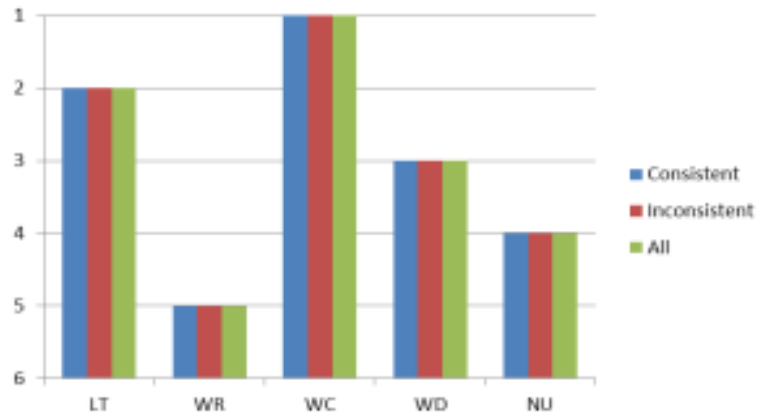

Figure 7: Graph showing the rankings if the consistent, inconsistent and all judgements were aggregated in analysing the Environmental Impacts ( 1 being the most significant and 5 being the least significant)

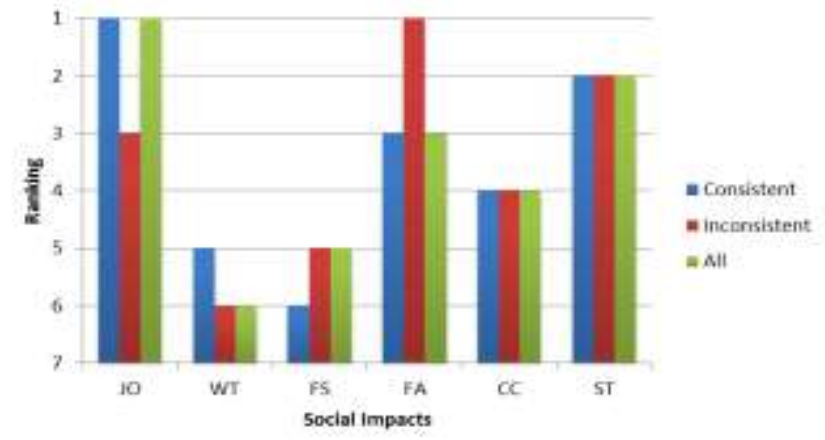

Figure 8: Graph showing the rankings if the consistent, inconsistent and all judgements were aggregated in analysing the social impacts ( 1 being the most significant and 6 being the least significant)

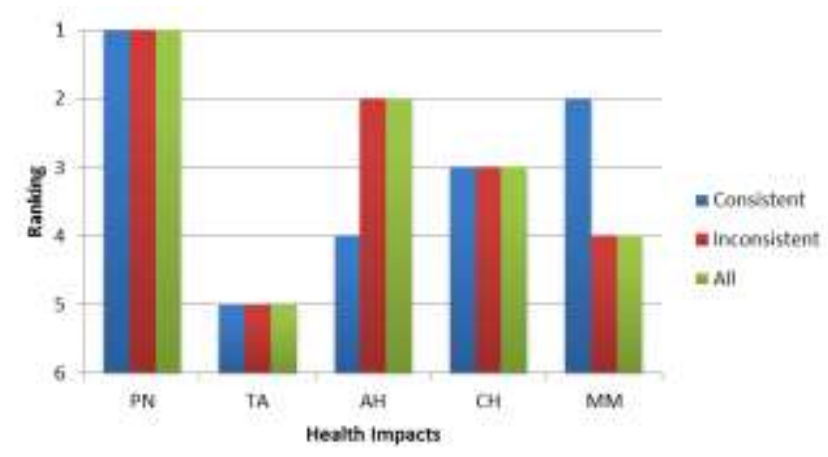

Figure 9: Graph showing the rankings if the consistent, inconsistent and all judgements were aggregated in analysing the health impacts ( 1 being the most significant and 5 being the least significant)

When the values of the experts were used as the only values gotten for the determination of significance, the rankings were different from when the public alone were used and when both the public and group were used as is evident in figures 10, 11 and 12. These differences could be because the opinions of experts were biassed towards saying the right things so that the project is approved without actually taking into account the impacts, but also it could be because the opinions of the members of the public are highly subjective and may be highly uninformed. The opinions of experts are based on knowledge and experience, but the opinions of public are based on how these impacts may have affected them individually and not about what these impacts truly represent. Choosing to use one set of opinions and not 
both is a mistake made many times in the execution of the EIA. It was evident that difference like there are the sources of serious issues between the Oil and Gas companies and the community.

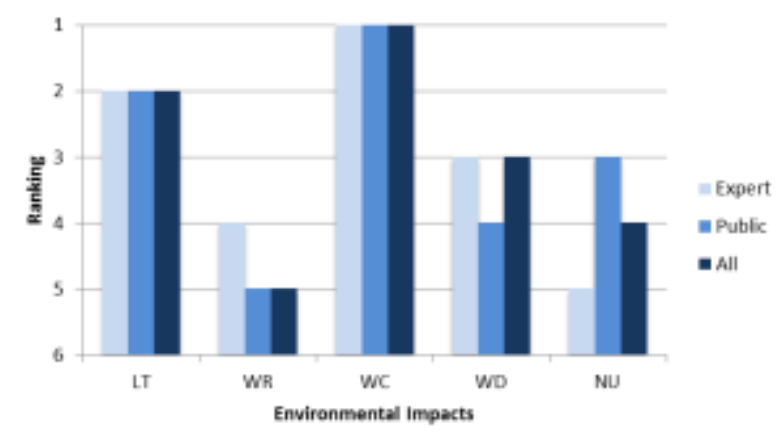

Figure 10. Graph showing the differences in ranks of Environmental Impacts when expert, public or both judgments are used ( 1 being the most significant and 5 being the least significant)

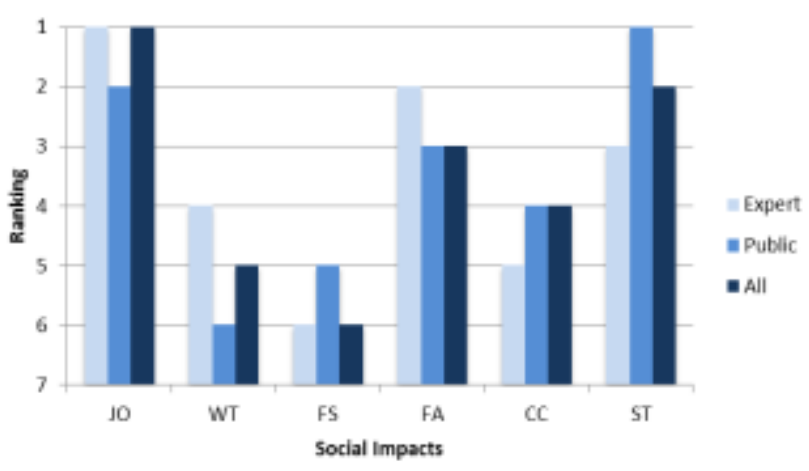

Figure 11. Graph showing the differences in ranks of Social Impacts when expert, public or both judgments are used ( 1 being the most significant and 6 being the east significant)

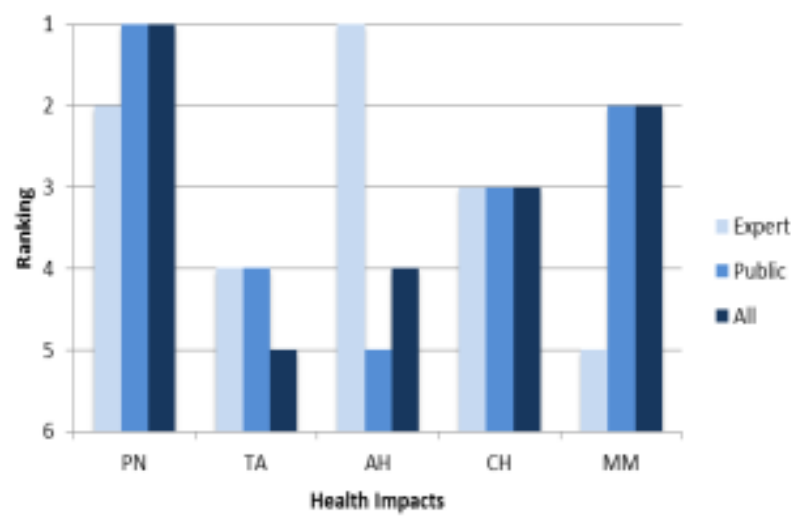

Figure 12. Graph showing the differences in ranks of Health Impacts when expert, public or both judgements are used (1 being the most significant and 5 being the least significant)

The differences observed in the ranks further buttress the importance of public participation because in the health impacts evaluation. For example, using only expert opinion would have yielded in the reduction of access to health care (AH) as the most significant impact which might be ok to the public (as it ranked 5th most significant to the public but is significant nonetheless looking at its weight). However, the public would suffer, and this could start a conflict, as an increase in morbidity and mortality rate (MM) which is 2 nd most significant to the public would be given 5 th priority by the expert. It is, however, interesting to notice that the opinions of both the experts and public were uniform on some impacts like LT, WC and $\mathrm{CH}$ (representing only $18.75 \%$ of all the identified impacts).

\section{Conclusion}

This study used the AHP in the impact significance determination stage of the EIA to investigate the effect of consistency and inconsistency in stakeholder judgement. The result demonstrated that although consistency in judgement is very important, it is not always obtained for every decision especially when dealing with many alternatives. Inconsistencies gave rise to differences in priority ranking which equals a difference in priority weights, which inadvertently affects the decision maker negatively. Differences were also observed in the global priorities when public opinion was included and when it was not. These differences could result in conflicts and issues between the companies and the host communities depending on the impact. There is, therefore, a need for public opinion to be taken into consideration throughout the EIA process.

Following from this study, it can, therefore, be said that the AHP is a critical tool for impact significance.

\section{Acknowledgment}

The authors wish to express their gratitude to every single person who took the time to fill out the questionnaire.

\section{References}

[1] G. Wood, "Thresholds And Criteria For Evaluating And Communicating Impact Significance In Environmental Statements: 'See No Evil, Hear No Evil, Speak No Evil'?,', Environmental Impact Assessment Review 28 (1), pp. 22-38, 2008.

[2] D. Lawrence, "Impact Significance Determination-Back To Basics," Environmental Impact Assessment Review 27 (8), pp. 755$769,2007$.

[3] R.. Khadka, A. Mathema, and U. Shrestha, "Determination of Significance of Environmental Impacts of Development Projects: A Case Study of Environmental Impact Assessment of Indrawati-3 Hydropower Project in Nepal," Journal of Environmental Protection 2 (8), pp. 1021-1031, 2011.

[4] A. Tenney, J. Kværner, and K. Gjerstad, "Uncertainty in Environmental Impact Assessment Predictions: The Need for Better Communication and More Transparency," Impact Assessment and Project Appraisal 24 (1), pp. 45-56, 2006.

[5]

[6] I. Huang, J. Keisler, and I. Linkov, "Multi-Criteria Decision Analysis in Environmental Sciences: Ten Years of Applications and Trends," Science of the Total Environment 409 (19), pp. 3578-3594, 2011.

[7] A. Glucker, P. Driessen, A. Kolhoff, and H. Runhaar, "Public Participation In Environmental Impact Assessment: Why, Who And How?," Environmental Impact Assessment Review 43, pp. 104-11, 2013.

[8] E. Condon, B. Golden, and E. Wasil, "Visualizing Group Decisions in the Analytic Hierarchy Process," Computers and Operations Research 30 (10), pp. 1435-1445, 2003. 
Proc. of the Fourth Intl. Conf. Advances in Bio-Informatics, Bio-Technology and Environmental Engineering- ABBE 2016

Copyright (C) Institute of Research Engineers and Doctors, USA .All rights reserved.

ISBN: 978-1-63248-091-0 doi: 10.15224/ 978-1-63248-091-0-62

[9] T. L. Saaty, and M. S. Ozdemir, "Why the Magic Number even Plus or Minus Two,' Mathematical and Computer Modelling 38, pp. 233 244, 2003.

[10] Y. Zhou, K. Maumbe, J. Deng, and S. Selin, "Resource-Based Destination Competitiveness Evaluation Using A Hybrid Analytic Hierarchy Process (AHP): The Case Study Of West Virginia," Tourism Management Perspectives 15, pp. 72-80, 2015.

[11] O. Sahin, S. Mohamed, J. Warnken, and A. Rahman, ' 'Assessment of Sea - Level Rise Adaptation Options,' ' Structural Survey 31 (4), pp. 283-300, 2013.

[12] R. W. Saaty, "The Analytic Hierarchy Process - What it is and How it is used," Mathematical Modelling 9(3-5), pp. 161-176, 1987.

[13] R. Ramanathan, "A Note on the Use of the Analytic Hierarchy Process for Environmental Impact Assessment," Journal of Environmental Management 63 (1), pp. 27-35, 2001.

[14] R. P. Singh, H. P. Nachtnebel, "Analytical hierarchy process (AHP) application for reinforcement of hydropower strategy in Nepal," Renewable and Sustainable Energy Reviews, Volume 55, pp. 43-58, 2016.

[15] M. Tavana, M. Zareinejad, D. D. Caprio, M. A. Kaviani, "An integrated intuitionistic fuzzy AHP and SWOT method for outsourcing reverse logistics,' Applied Soft Computing, Volume 40, pp. 544-557, 2016.

[16] Q. Dong, O. Cooper, “A peer-to-peer dynamic adaptive consensus reaching model for the group AHP decision-making, 'European Journal of Operational Research,' Volume 250, Issue 2 pp. 521-530, 2016.

[17] Wang, X. R.. Li, F. Zhen, J. Zhang, "How smart is your tourist attraction?: Measuring tourist preferences of smart tourism attractions via a FCEM-AHP and IPA approach," Tourism Management, Volume 54, pp. 309-320, 2016. 